\title{
An 11-year validation of wave-surge modelling in the Irish Sea, using a nested POLCOMS-WAM modelling system.
}

\author{
Jennifer M. Brown ${ }^{\text {a, }}$, Alejandro J. Souza ${ }^{\text {a }}$, Judith Wolf ${ }^{\text {a }}$ \\ a Proudman Oceanographic Laboratory, Joseph Proudman Building, 6 Brownlow \\ Street, Liverpool, L3 5DA, UK. \\ * Corresponding author Phone: +44 (0) 151795 4971, Fax: +44 (0) 151795 4801, \\ Email: jebro@pol.ac.uk (J.M. Brown)
}

Submitted to Ocean Modelling

\begin{abstract}
In the future it is believed that extreme coastal flooding events will increase (in frequency and intensity) as a result of climate change. We are investigating the flood risks in the eastern Irish Sea posed by extreme storm events. Here, an 11-year simulation $(01 / 01 / 1996-01 / 01 / 2007)$ including wave-current interaction has been validated. These data can then be used to investigate the potential for coastal flooding in the study area.
\end{abstract}

To accurately model a storm event in the eastern Irish Sea both wave effects and the influence of the external surge need to be considered. To simulate the waves, we have set up a one-way nested approach from a $1^{\circ}$ North Atlantic model, to a $1.85 \mathrm{~km}$ Irish Sea model, using the state-of-the-art $3^{\text {rd }}$-generation spectral Wave Model 
(WAM). This allows the influence of swell to be correctly represented. The Proudman Oceanographic Laboratory Coastal Ocean Modelling System (POLCOMS) has been used to model the tide-surge interaction. To include the external surge we have set up a one-way nested approach from the $1 / 9^{\circ}$ by $1 / 6^{\circ}$ Operational Continental Shelf surge model, to a $1.85 \mathrm{~km}$ Irish Sea model. At the medium resolution Irish Sea model we use a POLCOMS-WAM coupled model, to allow the effects of wavecurrent interaction on the prediction of surges at the coast.

Using two classification schemes the coupled model is shown to be good and often very good at predicting the surge, total water elevation and wave conditions. We also find the number of low level surge events has increased in the study area over the past decade. This time period is too short to determine any long-term trends in the wave and surge conditions.

Keywords: Wave-tide-surge modelling, Long-term model validation, POLCOMS, WAM, Model nesting, eastern Irish Sea.

\section{Introduction}

Flood prone areas continue to become more densely populated. It is believed that increased coastal flooding in both intensity and frequency will occur in response to global warming (e.g. Houghton, 2005) and climate change (IPCC, 2007). Sea level rise combined with human development on wetlands has lead to increased damage by coastal flooding (IPCC, 2007). The increasing threat of coastal flooding is therefore a cause of great concern for individual citizens, businesses and those charged with management and protection of the coast (e.g. Lowe et al., 2001). The Coastal Flooding by Extreme Events (CoFEE) project and Morphological Impacts and 
COastal Risks induced by Extreme storm events (MICORE) project are assessing past, present and future flood risk for a range of coastal environments due to extreme events (Brown et al., 2009; Wolf et al., 2008). Through the use of advanced modelling techniques (described in section 2) an 11-year wave-surge hindcast has been performed for the Irish Sea (Figure 1). Here we examine the long-term model validation (section 3) of both WAM and POLCOMS-WAM at different grid scales. An initial analysis of the modelling results and data has determined the extreme surge levels and wave heights that occur in Liverpool Bay. Further investigation will later be carried out to distinguish the different causes of extreme present day conditions in the eastern Irish Sea. The basic causes are discussed in Section 6. The most extreme events will be selected to investigate surges within Liverpool Bay (Figure 1) using a higher resolution model. This area provides a range of different coastal environments, providing examples of most of England's coastal types, and also has the added benefit of a vast and available dataset (POL Coastal Observatory).

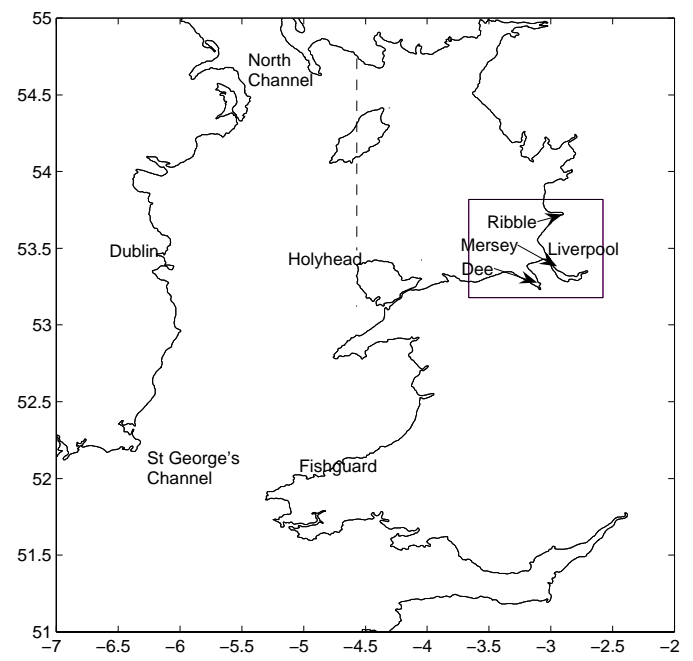

Fig. 1. The model area showing the Liverpool Bay model extent nested within the Irish Sea model. The vertical dashed line defines the boundary of the eastern Irish Sea. 
The occurrence of extreme high water levels and waves are considered more important than rising sea level with regard to changes in the dune morphology along the Sefton coast (Pye and Blott, 2008). More frequent and longer lasting extreme tidal levels have occurred in Liverpool Bay since 1990. Mean high water spring tide level reaches $4.17 \mathrm{~m}$ above mean tidal level (MTL) at Liverpool and $4.53 \mathrm{~m}$ (MTL) at Heysham. At these locations the spring tidal range is $8.22 \mathrm{~m}$ and $8.47 \mathrm{~m}$, respectively and the highest astronomical tide is $5.14 \mathrm{~m}$ (MTL) and 5.62m (MTL), respectively (Pye and Blott, 2008). The largest historical surge reached $2.47 \mathrm{~m}$ on the $26^{\text {th }}$ February 1990. The five largest observed high water levels occurred in 1977, 1983, 1990 (two events) and 1997. The surge levels during these high waters were between 0.68m and 1.43m (Pye and Blott, 2008). A longer data set for Liverpool (Woodworth and Blackman, 2002) found the most extreme high water levels occurred in 1905. Other long-term records reveal that the worst storm to afflict Liverpool occurred at midnight on the $6^{\text {th }}$ January 1839 resulting in significant localized loss. While server damage due to coastal flooding throughout Lancaster and Merseyside resulted from a surge driven by SSW winds on the $28^{\text {th }}-29^{\text {th }}$ October 1927 (Lamb, 1991). For surges in Liverpool Bay the flow into the Irish Sea through the North Channel and Celtic Sea (the external surge) is about equally as important as the locally generated surge (Jones and Davies, 1998). A nested modelling system must therefore be adopted. Wave conditions may also be critical to coastal flooding, through overtopping of sea defences and low-lying areas. The prevailing winds at this site are south-westerly. The largest waves and surges in Liverpool Bay are generated by westerly and northwesterly winds which have the longest fetch up to 200m (Wolf, 2008; Pye and Blott, 2008). Refraction focuses the waves onto Formby point (Pye and Blott, 2008). 
Liverpool Bay is sheltered from swell waves from the Atlantic and experiences locally wind-generated sea (Brown and Wolf, 2009). It is therefore less important to include external wave forcing with regard to this region, but this is important in central and southern parts of the Irish Sea. The wave height typically exceeds $3 \mathrm{~m}$ during 5-10 events per year and exceeds $4 \mathrm{~m}$ from $1-5$ times per year. The extreme 1 in 50 year wave height is estimated to be $5.5 \mathrm{~m}$ (Wolf, 2008). Wind waves are the mechanism through which the wind-stress interacts with the sea surface and the surface roughness is related to wave age. Local conditions may mean that waves are not in equilibrium with the wind so it is of benefit to model surge and waves simultaneously in a coupled modelling system. We use the Proudman Oceanographic Laboratory Coastal Modelling System (POLCOMS) as the surge model and the $3^{\text {rd }}$ generation spectral Wave Model (WAM). The November 1977 and January 2007 storm surge events have been previously used to calibrate the surge prediction in the eastern Irish Sea using this coupled wave-tide-surge (POLCOMS-WAM) model (Brown and Wolf, 2009).

Within the study area there is a vast and available data set to validate the modelling systems. Met Office $12 \mathrm{~km}$ wind data are available to drive the models and tide gauge data around the U.K. are held at the British Oceanographic Data Centre (BODC) to validate the surge hindcast. Wave data have been recorded in Liverpool Bay since October 2002, and other wave buoy data around the U.K. are available for the decadal period of interest from the Irish Marine Institute and U.K. Met Office. The main focus of the modelling will be to assess the impacts of extreme events on the morphology of the Sefton coastline, north of Liverpool. 
The aim of this paper is to validate the 11-year hindcast of wave and hydrodynamic conditions around the U.K. The modelling methods are presented in section 2, followed in section 3 by validation of the coarse and medium resolution model results. An assessment of the wind forcing is also presented in section 3. The results are

presented in section 4 , followed in section 5 by an estimate of the return period of extreme events along the Sefton Coastline. A discussion of the results and methods to assess the model validity is made in Section 6. The conclusions are finally drawn on the validity of the hindcast modelling results in section 7 .

\section{Method}

The coupled POLCOMS-WAM system has been under development at the Proudman Oceanographic Laboratory for the last 6 years. We apply it here, using a parallel computer system (Ashworth et al., 2004), to the $1.85 \mathrm{~km}$ Irish Sea model (Figure 1).

In order to accurately simulate the waves in the study area, we use the state-of-the-art $3^{\text {rd }}$-generation spectral Wave Model (WAM, Komen et al., 1994). In the coupled Irish Sea model, a modified version of WAM for shallow water (Monbaliu et al., 2000) has been applied. Following Osuna et al (2007) WAM simulates the 2D wave spectral evolution considering the energy input by wind, energy dissipation by whitecapping and bottom friction, and non-linear wave-wave interactions. Depth-limited wavebreaking has not been included in this simulation, but will later be included in the Liverpool Bay model application in which drying areas are included. Externally generated waves propagating into the Irish Sea are included by adopting a one-way nested model approach. A $1^{\mathrm{o}}$ northeast Atlantic model provides hourly boundary forcing for the $1.85 \mathrm{~km}$ Irish Sea model (Figure 2). This coarse grid model was driven 
by six-hourly, $\sim 1^{\circ}$ resolution ECMWF (reanalyzed ERA-40) wind data. In the coupled Irish Sea model (detailed in Osuna and Wolf, 2005) WAM uses the same wind forcing provided via the surge model, using hourly Met Office mesoscale model winds (see below).

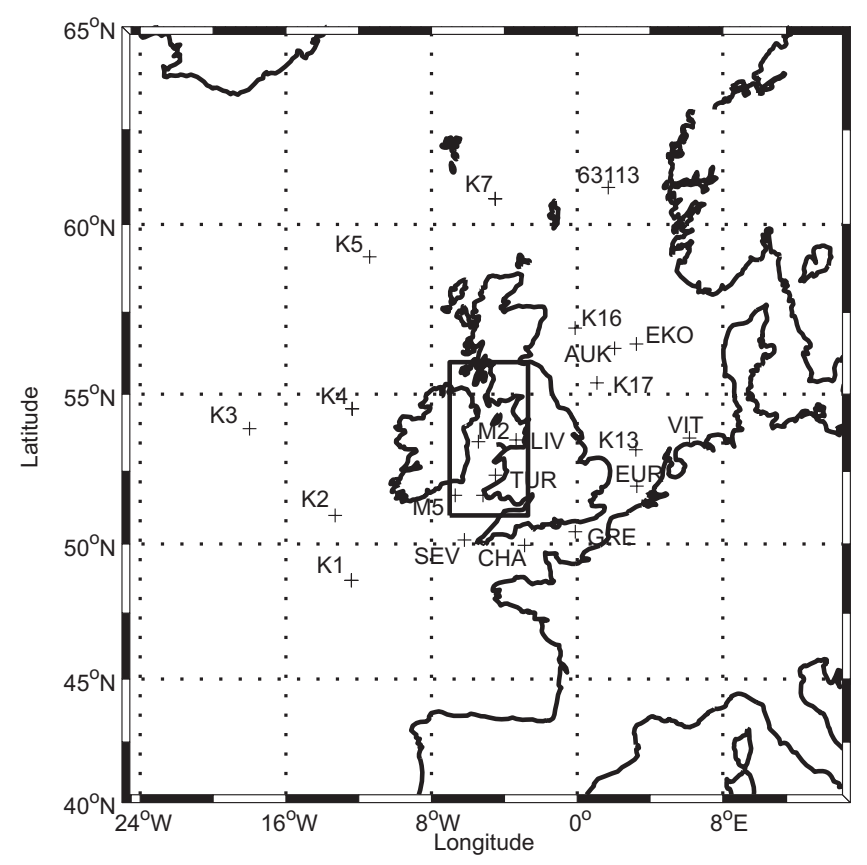

Fig. 2. The nested WAM model domains and the locations of the wave buoys and offshore platforms used for validation. The outer boundary of the figure represents the northeast Atlantic model and the inner rectangular box represents the Irish Sea model boundary.

To simulate the tides and surge within the Irish Sea we use the hydrodynamic model POLCOMS (Proudman Oceanographic Laboratory Coastal-Ocean Modelling System), a three dimensional primitive equation numerical model. The model is formulated in spherical polar coordinates on a B-grid with a terrain following (sigma) coordinate system in the vertical (Holt and James 2001). POLCOMS can simulate both the barotropic and baroclinic processes, which arise from the tides, 
meteorological and riverine forcing (although density effects have not been included here). The turbulence closure scheme (Mellor and Yamada, 1982) has been modified to account for surface wave breaking (Craig and Banner, 1994). For the 11-year hindcast hourly wind and pressure data were provided by the UK Met Office North East Atlantic (mesoscale) model, with a resolution of $1 / 9^{\circ}$ by $1 / 6^{\circ}(\sim 12 \mathrm{~km})$. Such a three dimensional model is required to represent the vertical structure of the windinduced currents (Jones and Davies, 1998) when modelling surge events. To capture the external surge generated outside of the Irish Sea a one-way nested approach (Figure 3 ) from the $1 / 9^{\circ}$ by $1 / 6^{\circ}(\sim 12 \mathrm{~km})$ operational surge model (run at Proudman) to the $1.8 \mathrm{~km}$ POLCOMS Irish Sea model, has been applied. The operational surge model (details of which can be found in Flather, 1994) provided total (tide plus surge) hourly elevation and velocity boundary forcing.

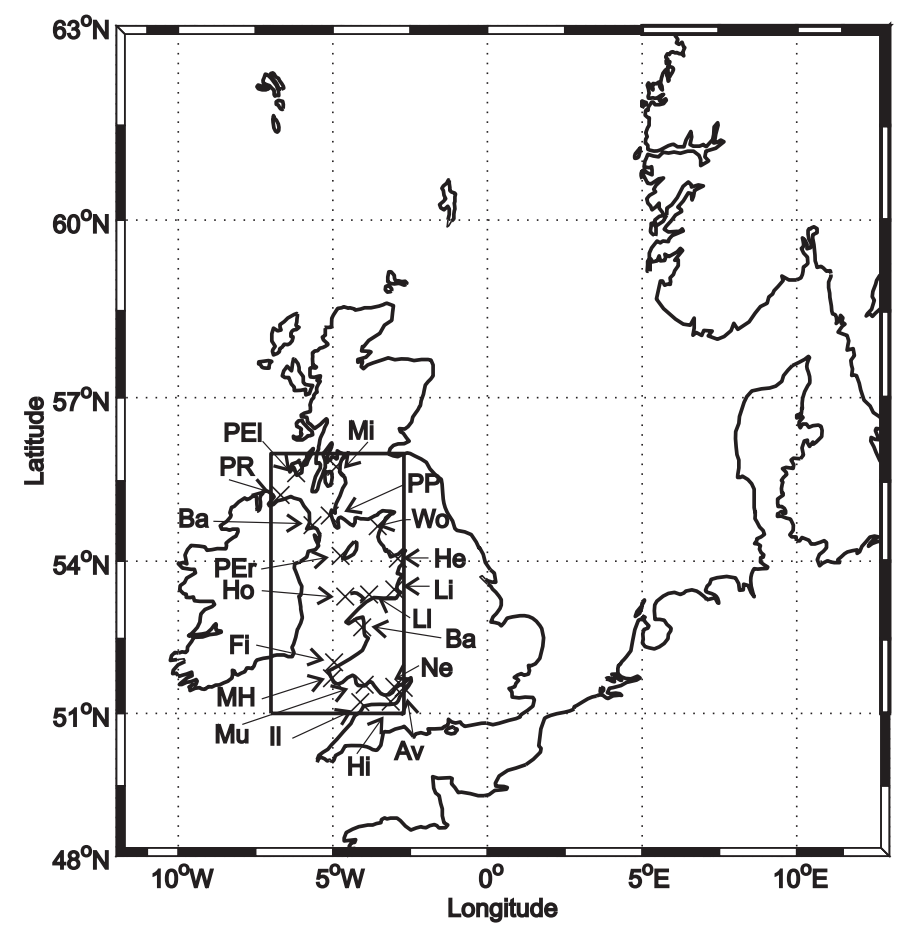


Fig. 3. The Irish Sea POLCOMS model domain (the inner box) nested within the Operational surge model domain (the outer figure boundary). The locations of the tide gauge stations are also represented.

For the Irish Sea model wave-tide-surge interaction has been taken into account by 2way coupling of POLCOMS and WAM (Osuna and Wolf, 2005). The coupling is achieved through the surface and bottom stress and wave refraction due to the presence of time varying current and elevation fields (Wolf et al., 2002). Presently, radiation stress is not included within the coupled model, but is under development. The surface stress formulation allows waves to influence the surface roughness in the surge simulation using the method of Charnock (1955), with a wave dependent Charnock parameter (Janssen, 2004). The effect of waves on bottom friction is estimated using the method of Madsen (1994). In the standard POLCOMS-WAM model the minimum water depth was set to $10 \mathrm{~m}$, but for this research, in which we are focusing on Liverpool Bay, improved bathymetric data (NOOS data set: Zijderveld and Verlaan, 2004) in the eastern Irish Sea has allowed a 5m minimum water depth to be applied to this region only. This minimum depth allowed resolution of the coastal bathymetric features, but prevented numerical instability with drying areas occurring in the model domain due to the tidal variations. This gave improved surge prediction locally within the eastern Irish Sea (Brown and Wolf, 2009). The next step in the model study is planned using a Liverpool Bay model with a 'wetting and drying' scheme, which will eliminate the need to fix a minimum depth.

\subsection{Surge definitions}


We define the filtered surge as the residual obtained by filtering out all periodic signal from the (modelled and observed) total water elevation. To do this the Matlab function 'filtfilt' is used. The $\mathrm{M}_{4}$ (smallest) and $\mathrm{O}_{1}$ (largest) tidal periods are used to set the range of tidal signals that are to be removed in the filtering process. This filtered surge is the result of the meteorological forcing alone. However, in the eastern Irish Sea tide-surge interaction significantly modifies the surge (Brown and Wolf, 2009). This modification has significant effect on both the timing and size of the peak surge. The additional water elevation on top of the predicted tidal elevation is commonly known as the surge (residual). We apply the Proudman Oceanographic Laboratory Coastal Observatory tidal analysis program (Titan) to the total elevation to 'de-tide' the modelled prediction. The program is based on the Task 2000 package from the National Tide and Sea Level Facility (see http://www.pol.ac.uk/ntslf/software.html). This extracts surge residuals that are consistent with those provided as part of the tide gauge data set. Using tidal analysis is also less computationally expensive than generating an 11-year hindcast of the modelled tide.

\subsection{Error metrics}

Allen et al. (2007) presents a set of error statistics to use for complex 3D modelling systems. We use two of these measures of accuracy to validate the 11-year model predictions compared to the data. In the following equations $M$ represents the model prediction, $D$ represents the measured data and $N$ is the number of data points in the 11-year hindcast period. The first measure is the Percentage Model Bias (Pbias). This provides a measure of whether the model is systematically under- or over- 
estimating the measured data. This is achieved by normalizing the sum of the model error by the data:

$$
\text { Pbias }=100 \frac{\sum_{n=1}^{N}\left(D_{n}-M_{n}\right)}{\sum_{n=1}^{N} D_{n}}
$$

The better the model the closer the value is to zero. The level of accuracy is quantified as follows $\mid$ Pbias $\mid<10$ excellent, $10-20$ very good, $20-40$ good, $>40$ poor. Although Equation (1) works well for parameters that always maintain a positive value (e.g. $H_{s}$ and $T_{p}$ ), it can be problematic for parameters which oscillate around zero (e.g. tides and surge). For the validations made here we modify Equation (1) to be:

Pbias $=100 \frac{\sum_{n=1}^{N}\left(\left|D_{n}\right|-\left|M_{n}\right|\right)}{\sum_{n=1}^{N}\left|D_{n}\right|}$

otherwise the summation of the data and the error can create a large Pbias, even when the model is performing well. Also, the true systematic under- or over-prediction of the model may not be correctly calculated.

The second metric is the Cost Function $(C F)$. This non-dimensional measure quantifies the 'goodness of fit' between the model and the observations. It is the ratio of model mismatch to the variance (standard deviation of the data, $\sigma_{D}$ ) in the data:

$C F=\frac{1}{N} \sum_{n=1}^{N} \frac{\left|D_{n}-M_{n}\right|}{\sigma_{D}}$

The model performance is classified as follows: $C F<1$ very good, $1-2 \operatorname{good}, 2-3$ reasonable, $>3$ poor. 


\section{Model validations}

In this section we present the validation of the 11-year nested model hindcast. The POL operational surge model is known to give accurate surge predictions (Flather, 2000), and is regularly validated (monthly) with data from the UK national tide gauge network (see http://www.pol.ac.uk/ntslf/surgemonthlyplots) for operational use. We therefore concentrate on validation of the coarse WAM model of the northeast Atlantic and the medium resolution POLCOMS-WAM coupled model of the Irish Sea. The data selected to validate WAM are given in Table 1 and the wave buoy and platform locations are shown in Figure 2. The wave parameters are defined as follows: $H_{s}$ is the significant wave height, $T_{z}$ is the zero-crossing period and $T_{p}$ is the peak period. $H_{S}\left(H_{m 0}=4 \sqrt{ } m_{0}\right)$ and $T_{z}\left(T_{m 02}=\sqrt{ } m_{0} / \sqrt{ }_{m_{2}}\right)$ are both derived from spectral moments $\left(m_{k}\right.$, Krogstad et al., 1999). $T_{p}$ is a rather unstable parameter compared with $T_{z}$, since for multi-modal spectra the peak can irregularly change frequency (Krogstad et al., 1999). Unfortunately, $T_{p}$ is often the only available observed wave period parameter (Table 1) and therefore model validation can show the model to be less accurate than if $T_{z}$ was used.

Coastal tide gauges around the U.K. were used to validate POLCOMS; the positions of the chosen stations are shown in Figure 3. The periods for which data were available at each tide gauge location are given in Table 2. For POLCOMS we validate not only the total water elevation (MTL) but also the different surge components defined in section 2.1.

\begin{tabular}{|l|l|l|}
\hline Location & Data available & Data used \\
\hline K2 & $1991-2007$ & $H_{s}, T_{p}$ \\
\hline K5 & $1994-2007$ & $H_{s}, T_{p}$ \\
\hline 63113 & $1998-2007$ & $H_{s}, T_{p}$ \\
\hline
\end{tabular}




\begin{tabular}{|l|l|l|}
\hline K17 & $1995-2005$ & $H_{s}, T_{p}$ \\
\hline Seven Stones LV (SEV) & $1995-2004$ & $H_{s}, T_{p}$ \\
\hline M5 & $2004-2007$ & $H_{s}, T_{p}$ \\
\hline Channel LV (CHA) & $1996-2005$ & $H_{s}, T_{p}$ \\
\hline Greenwich (GRE) & $1994-2005$ & $H_{s}, T_{p}$ \\
\hline K1 & $2000-2004$ & $H_{s}, T_{p}$ \\
\hline K3 & $2000-2004$ & $H_{s}, T_{p}$ \\
\hline K16 & $1995-2003$ & $H_{s}, T_{p}$ \\
\hline Turbot Bank (TUR) & $1998-2005$ & $H_{s}, T_{p}$ \\
\hline Ekofisk (EKO) & $2003-2004$ & $H_{s}, T_{z}$ \\
\hline K13 & $1996-2001$ & $H_{s}, T_{z}$ \\
\hline Euro (EUR) & $1996-2001$ & $H_{s}, T_{z}$ \\
\hline VTN SON (VTN) & $1996-2001$ & $H_{s}, T_{z}$ \\
\hline AUK & $2000-2003$ & $H_{s}, T_{p}$ \\
\hline K4 & $2000-2004$ & $H_{s}, T_{p}$ \\
\hline K7 & $2000-2004$ & $H_{s}, T_{p}$ \\
\hline M2 & $2001-2007$ & $H_{s}, T_{p}$ \\
\hline Aberporth (ABE) & $1994-2005$ & $H_{s}, T_{p}$ \\
\hline Liverpool Bay (LIV) & $2002-2007$ & $H_{s}, T_{p}$ \\
\hline
\end{tabular}

Table 1: Available wave data used to validate the 11-year wave hindcast.

\begin{tabular}{|l|l|}
\hline Location & Data available \\
\hline Port Rush (PR) & $1996-2007$ \\
\hline Port Ellen (PEl) & $1996-2007$ \\
\hline Millport (Mi) & $1996-2007$ \\
\hline Bangor (Ban) & $1996-2007$ \\
\hline Port Patrick (PP) & $1996-2007$ \\
\hline Workington (Wo) & $1996-2007$ \\
\hline Port Erin (PEr) & $1998-2007$ \\
\hline Heysham (He) & $1996-2007$ \\
\hline Liverpool (Li) & $1996-2007$ \\
\hline Llandudno (Ll) & $1996-2007$ \\
\hline Holyhead (Ho) & $1996-2007$ \\
\hline Barmouth (Bar) & $1996-2007$ \\
\hline Fishguard (Fi) & $1996-2007$ \\
\hline Milford Haven (MH) & $1996-2007$ \\
\hline Mumbles (Mu) & $1997-2007$ \\
\hline Newport (Ne) & $1996-2007$ \\
\hline Avonmouth (Av) & $1996-2007$ \\
\hline Hinkley Point (Hi) & $1996-2007$ \\
\hline Ilfracombe (Il) & $1996-2007$ \\
\hline
\end{tabular}

Table 2: Available total water elevation data used to validate the 11-year hydrodynamic hindcast.

\subsection{North East Atlantic (NEA) WAM validation}


The 11-year (1996-2006) northeast Atlantic WAM model hindcast is compared with wave data collected around the U.K. Not all of the locations within the Irish Sea are used in the validation since the model is too coarse to resolve the details of the Irish Sea. Table 3 gives the performance metrics for the model.

\begin{tabular}{|l|l|l|l|l|}
\hline Location & Pbias $H_{S}(\%)$ & Pbias $T(\%)$ & $C F H_{S}$ & $C F T$ \\
\hline K2 & -28.7737 & 11.7117 & 0.5740 & 0.8913 \\
\hline K5 & -28.2662 & 13.7498 & 0.5501 & 0.9525 \\
\hline 63113 & -18.4596 & 23.0821 & 0.3782 & 1.1965 \\
\hline K17 & -28.1119 & 11.4587 & 0.5132 & 0.9166 \\
\hline Seven Stones LV (SEV) & -11.5019 & -8.8817 & 0.3831 & 0.9447 \\
\hline M5 & -30.8981 & 21.1849 & 0.5280 & 1.2150 \\
\hline Channel LV (CHA) & -9.3614 & -15.0275 & 0.3713 & 1.0526 \\
\hline Greenwich (GRE) & 11.7389 & -8.5982 & 0.3856 & 1.0501 \\
\hline K1 & -28.4246 & 10.2943 & 0.5682 & 0.8950 \\
\hline K3 & -28.5078 & 6.8208 & 0.6375 & 0.8249 \\
\hline K16 & -28.0855 & 10.6327 & 0.5255 & 0.9034 \\
\hline Turbot Bank (TUR) & -27.6989 & 4.9711 & 0.4908 & 1.1217 \\
\hline Ekofisk (EKO) & -11.8922 & -8.3807 & 0.2988 & 0.4639 \\
\hline K13 & -13.5950 & -10.7338 & 0.3440 & 0.7170 \\
\hline Euro (EUR) & -12.9723 & -6.2893 & 0.3901 & 0.7700 \\
\hline VTN SON (VTN) & 33.8081 & -1.4307 & 0.6090 & 0.6424 \\
\hline AUK & -17.4478 & 22.6791 & 0.3538 & 1.2331 \\
\hline K4 & -28.1923 & 11.1235 & 0.5591 & 0.8799 \\
\hline K7 & -21.7120 & 14.5545 & 0.6839 & 1.1027 \\
\hline
\end{tabular}

Table 3: Performance metrics for the NEA WAM model 11-year hindcast. The locations are given in Figure 2, $H_{s}=$ significant wave height and $T=$ wave period either the peak $\left(T_{p}\right)$ or zero up crossing period $\left(T_{z}\right)$ depending on the data available, given in Table 1.

The Pbias results (Table 3) show the model simulation is very good and even excellent at a few locations, which are often comparatively close to the coast. We find the model is better as simulating $T$ than $H_{s}$ (for this metric) at every location. Excellence is also achieved more frequently in $T$ than $H_{s}$. For $H_{s}$ the model generally under-predicts the measured data, while for $T$ the model often over predicts the 
measured data (a result of the inverse relation between the two parameters). This is likely to be due to the low resolution (in space and time) of the wind forcing. The $C F$ metric confirms the model performance to be very good, but $H_{s}$ has a better 'goodness of fit' than $T$. The best model performance based on this metric occurs within the English Channel and at certain locations across the North Sea.

\subsection{Irish Sea (IRS) POLCOMS-WAM validation}

The Irish Sea POLCOMS-WAM model has been validated at 19 tide gauges (Table 4) and 5 wave buoys (Table 5). The metrics used to assess the model's performance show the model to be very good to good across this region.

\begin{tabular}{|l|l|l|l|l|l|l|}
\hline Location & Pbias T & Pbias TS & Pbias FS & CF T & $C F$ TS & $C F$ FS \\
\hline Port Rush (PR) & -25.0803 & -8.5105 & -28.6086 & 0.5596 & 0.3988 & 0.5919 \\
\hline Port Ellen (PEl) & 69.2934 & -9.0171 & -27.5122 & 1.1017 & 0.4106 & 0.8109 \\
\hline Millport (Mi) & 2.7907 & -8.4767 & -9.3759 & 0.2713 & 0.4129 & 0.3301 \\
\hline Port Patrick (PP) & -5.1172 & -9.2709 & -20.2224 & 0.2102 & 0.4191 & 0.4775 \\
\hline Bangor (Ban) & -7.2520 & -6.1907 & -6.6766 & 0.2593 & 0.4048 & 0.3278 \\
\hline Port Erin (PEr) & -6.5211 & -16.6321 & -23.1098 & 0.1471 & 0.4697 & 0.6056 \\
\hline Workington (Wo) & -3.0214 & -21.3224 & -7.6096 & 0.1122 & 0.6003 & 0.2876 \\
\hline Heysham (He) & -5.4816 & 3.4692 & -16.8650 & 0.2270 & 0.6631 & 0.5819 \\
\hline Liverpool (Li) & -5.8569 & -12.8323 & -16.0574 & 0.0716 & 0.4726 & 0.3688 \\
\hline Llandudno (Ll) & -4.0079 & -10.7041 & -13.1189 & 0.0935 & 0.4639 & 0.4117 \\
\hline Holyhead (Ho) & -3.5758 & -6.6986 & 2.3802 & 0.1108 & 0.4284 & 0.5095 \\
\hline Barmouth (Bar) & 3.3836 & -15.6499 & -17.4029 & 0.1317 & 0.4641 & 0.3009 \\
\hline Fishguard (Fi) & 1.3483 & -20.2246 & -28.3692 & 0.1751 & 0.6023 & 0.8579 \\
\hline Milford Haven (MH) & -3.5384 & -14.0975 & -17.2682 & 0.1533 & 0.5818 & 0.5413 \\
\hline Mumbles (Mu) & -0.9666 & -18.2050 & -40.2640 & 0.1360 & 0.5344 & 0.8787 \\
\hline Newport (Ne) & 5.7330 & -20.0106 & -18.4550 & 0.1020 & 0.6415 & 0.4076 \\
\hline Avonmouth (Av) & 5.2947 & -21.4378 & -21.4233 & 0.1506 & 0.6774 & 0.4227 \\
\hline Hinkley Point (Hi) & 4.0177 & -15.4398 & -50.7231 & 0.1007 & 0.5936 & 1.2953 \\
\hline Ilfracombe (Il) & -1.4125 & -15.0045 & -8.9748 & 0.1345 & 0.5749 & 0.2601 \\
\hline
\end{tabular}

Table 4: Performance metrics for the IRS POLCOMS model 11-year hindcast. The

locations are given in Figure 1, T = total water elevation (MTL), TS = tide-surge residual and $\mathrm{FS}=$ filtered surge residual. 


\begin{tabular}{|l|l|l|l|l|}
\hline Location & ${\text { Pbias } H_{S}}$ & Pbias $T_{p}$ & $C F H_{s}$ & $C F T_{p}$ \\
\hline Aberporth & -23.4989 & 42.4145 & 0.4560 & 1.8109 \\
\hline Liverpool Bay & -37.9187 & 44.1666 & 0.5438 & 2.0815 \\
\hline M2 & -22.9647 & 19.2718 & 0.5278 & 1.7620 \\
\hline M5 & -14.3261 & 23.4532 & 0.3653 & 1.2118 \\
\hline Turbot Bank & -29.6608 & 12.2911 & 0.4830 & 1.1328 \\
\hline
\end{tabular}

Table 5: Performance metrics for the IRS WAM model 11-year hindcast. The locations are given in Figure 2, $H_{s}=$ significant wave height and $T_{p}=$ peak wave period.

We find POLCOMS does not consistently under- or over-estimate the water level across the domain, unlike WAM that constantly under-predicts $H_{s}$ across the region. This under-prediction could be related to the boundary forcing (negative pbias values for K1, K5, M5, Turbot Bank (TUR) and Seven Stones LV (SEV) in Table 1) or due to errors in the wind forcing. The POLCOMS model performs with a lower error than WAM, with the exception of Port Ellen. At this location the tidal range is noticeably over-predicted with much higher high water elevation being predicted. Removing the tidal component from the total water level to obtain the surge improves the validity at this location. This is likely to be due to poor resolution of the coastal bathymetry at this position, especially within the Operational Model forcing the boundary, which is close to this position. Generally, for POLCOMS the $\mid$ Pbias $\mid<30$ with $C F<2$ and often $\mid$ Pbias $\mid<10$ with $C F<1$ for POLCOMS, making this a very good model hindcast. Again WAM provides a good model hindcast with $\mid$ Pbias $\mid<38$ with $C F<$ 2.

\subsection{Wind validation in the Irish Sea (IRS)}

The accuracy of any model is dependent on the quality of the input data. We validate the mesoscale wind forcing for the IRS model using data from the Hilbre met station, 
situated at the mouth of the Dee Estuary $\left(53^{\circ} 22.94^{\prime} \mathrm{N}, 3^{\circ} 13.60^{\prime} \mathrm{W}\right)$. The data are available from $16^{\text {th }}$ April 2004 so only data between this date and $1^{\text {st }}$ January 2007 are validated. The mesoscale winds $(\sim 12 \mathrm{~km})$ are interpolated by POLCOMS onto the Irish Sea model grid $(\sim 1.8 \mathrm{~km})$. For the wind speed the pbias $=-38.5044$ and $C F=$ 0.7706 and for the wind direction pbias $=-21.7814$ and $C F=1.9198$. The model winds are classified by the $C F$ metric to be very good and the direction to be good, while the pbias metric shows the winds are lower than that observed. This may explain why the (locally generated) wave heights are generally under-predicted in the Irish Sea.

\section{Results}

Here we present the statistics of the occurrence of extreme wave and surge events. The 11-year hindcast and available data sets have been used to determine the most extreme peak surge elevations, high water (HW) levels and wave heights in Liverpool Bay. Trends in the extreme event are also investigated, but the length of the studied period prevents any significant long-term trends being determined. We investigate the observed surge levels, the filtered-surge residual and HW levels at two tide gauge locations, namely Heysham and Liverpool. These adjacent gauges encompass the full extent of the Sefton Coastline, which is the focus of the interest of the research programme. The surge residual allows analysis of the additional water level on top of the predicted tide due to a storm event interacting with the tide, whereas the filteredsurge allows analysis of the impact of meteorological forcing at the two locations. The waves are analysed at the wave buoy location within Liverpool Bay. 
We find that along the Sefton Coast the extreme surge elevations due to meteorological forcing (filtered surge) can reach $1.2 \mathrm{~m}$ at Liverpool and $1.4 \mathrm{~m}$ at Heysham (Figure 4). But when tide-surge interaction is accounted for the peak surge increases and the extremes can reach $2.3 \mathrm{~m}$ at Liverpool and $2.4 \mathrm{~m}$ at Heysham (Figure 5). The most extreme high water levels are not significantly greater than a typical spring tide HW of $\sim 5 \mathrm{~m}$ (MTL) at Liverpool. At Liverpool an extreme HW can reach 5.6m (MTL), while at Heysham, where the tidal range is larger with typical spring HW levels of 5.4m (MTL), they can reach 6.2m (MTL) (Figure 6). In addition to the increased water levels during a storm event, extreme waves of 5.6m (MTL) can also be generated in Liverpool Bay (Figure 7).
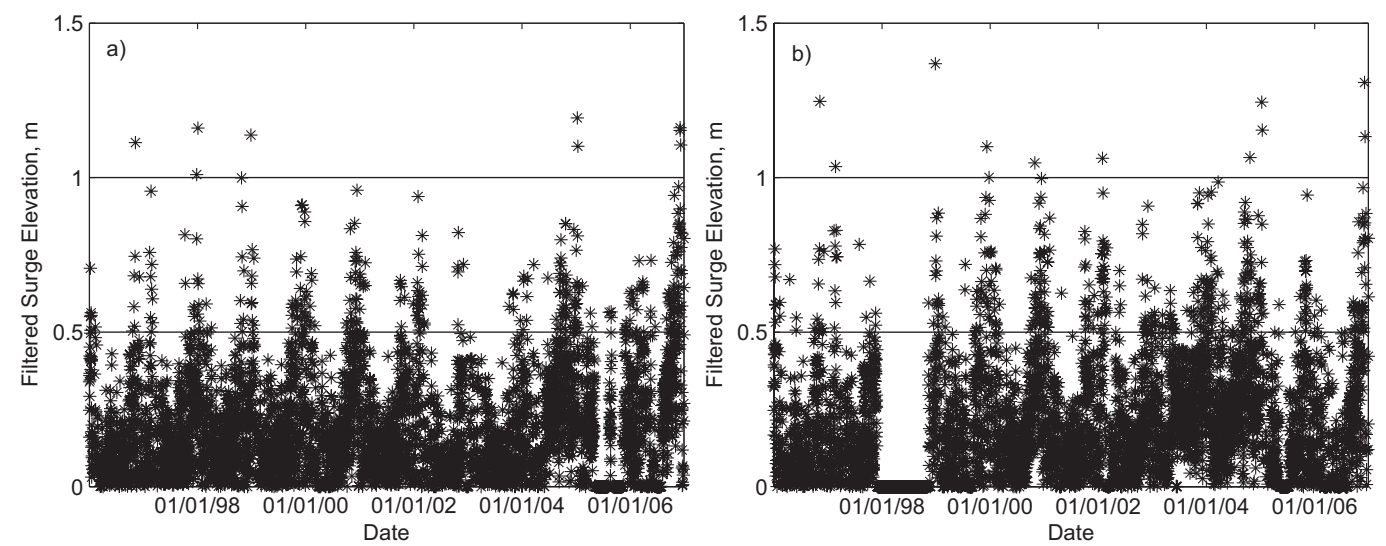

Fig. 4. The (positive) peak filtered surge residuals, due to the meteorological forcing alone, over the past 11-years, obtained from tide gauge data at a) Liverpool and b) Heysham. 

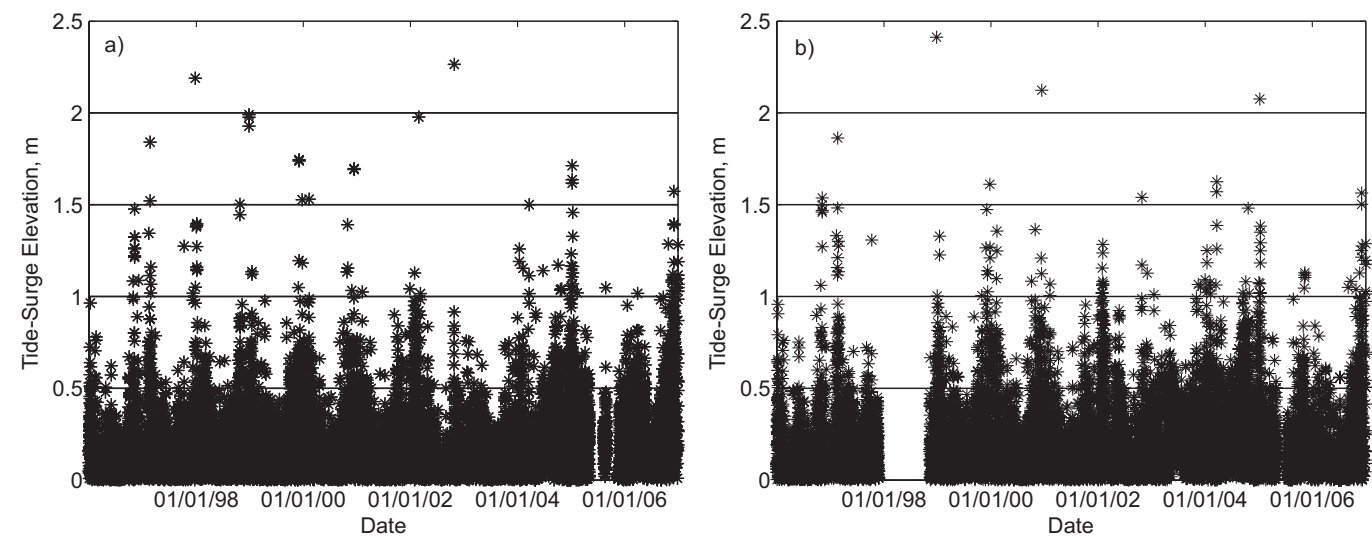

Fig. 5. The (positive) peak surge residuals, due to tide-surge interaction, over the past

11-years, obtained from tide gauge data at a) Liverpool and b) Heysham.
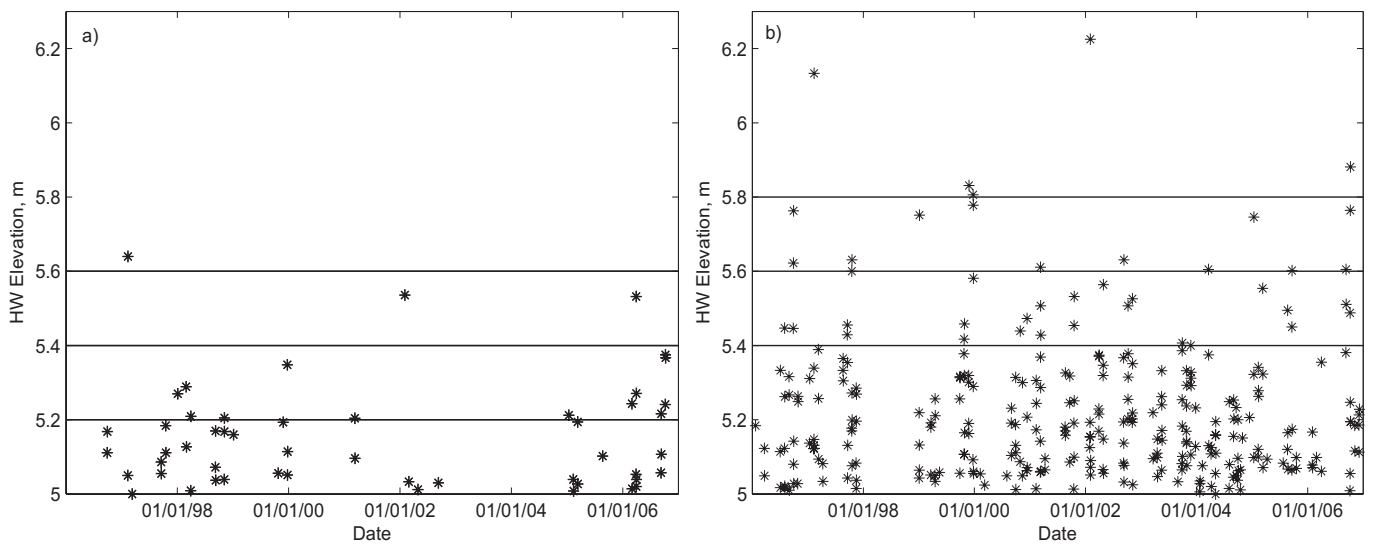

Fig. 6. High water elevations (above MTL) greater than $5 \mathrm{~m}$ over the past 11-years, obtained from tide gauge data at a) Liverpool and b) Heysham.

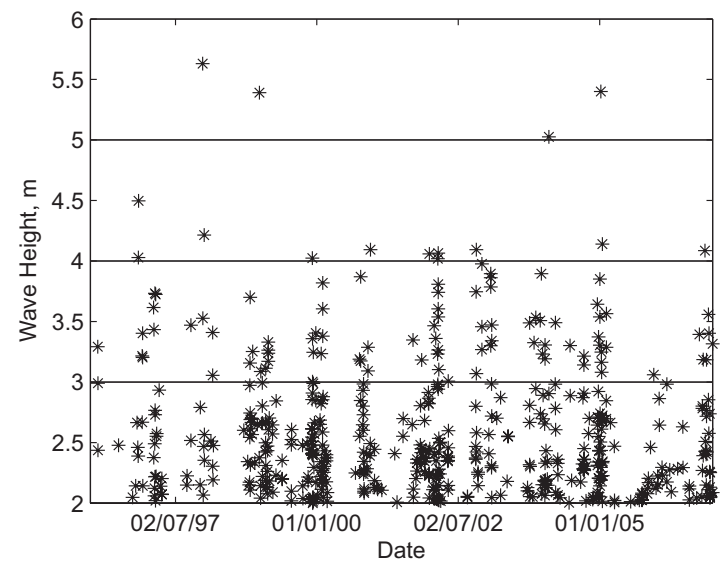

Fig. 7. Wave height greater than $2 \mathrm{~m}$ over the past 11-years, obtained from model hindcast data due to limited observations (02/10/02 onwards). 
Figure 8 shows periods when extreme high water levels coincided with extreme waves. There are more cases for Heysham since the tidal range is larger than at Liverpool, so high water more frequently exceeds $5 \mathrm{~m}$. If major wave conditions and water levels occur simultaneously at Liverpool the same is often true for Heysham ( 8 out of 13 events). Whether both ports simultaneously experience major events for a given storm depends on the storm track. This is being investigated further following Lennon (1963). When the times of HW coincide at both ports these cases are cause the slightly larger ' $\square$ ' to be covered by a ' $\square$ ' in Figure 8, creating a thicker outline, but if there is a lag in the time of observed high water these symbols align in the vertical. For Liverpool 13 major joint events occur and at Heysham 23 major joint events occur over the 11 year period investigated. Although Heysham experiences higher water levels the offshore waves during these high water conditions are within the same range as those when Liverpool experiences major water levels. These joint major conditions only occur between October and March. Over the 11 year period a bimodal cycle is evident (with peaks at the start and end of the study period and a trough early in 2003) in data. The years 2001 and 2003 are the only years when no simultaneous major events happen. This cyclic trend is not a consequence of the 18 year nodal tide. The tidal maxima occurred in 1997 and will occur again in 2015 and the tidal minima occurred in 2006 (Pugh, 2004). The trend could be liked to decadal trends in storm track position and the North Atlantic Oscillation (see Woodworth et al., 2007). 


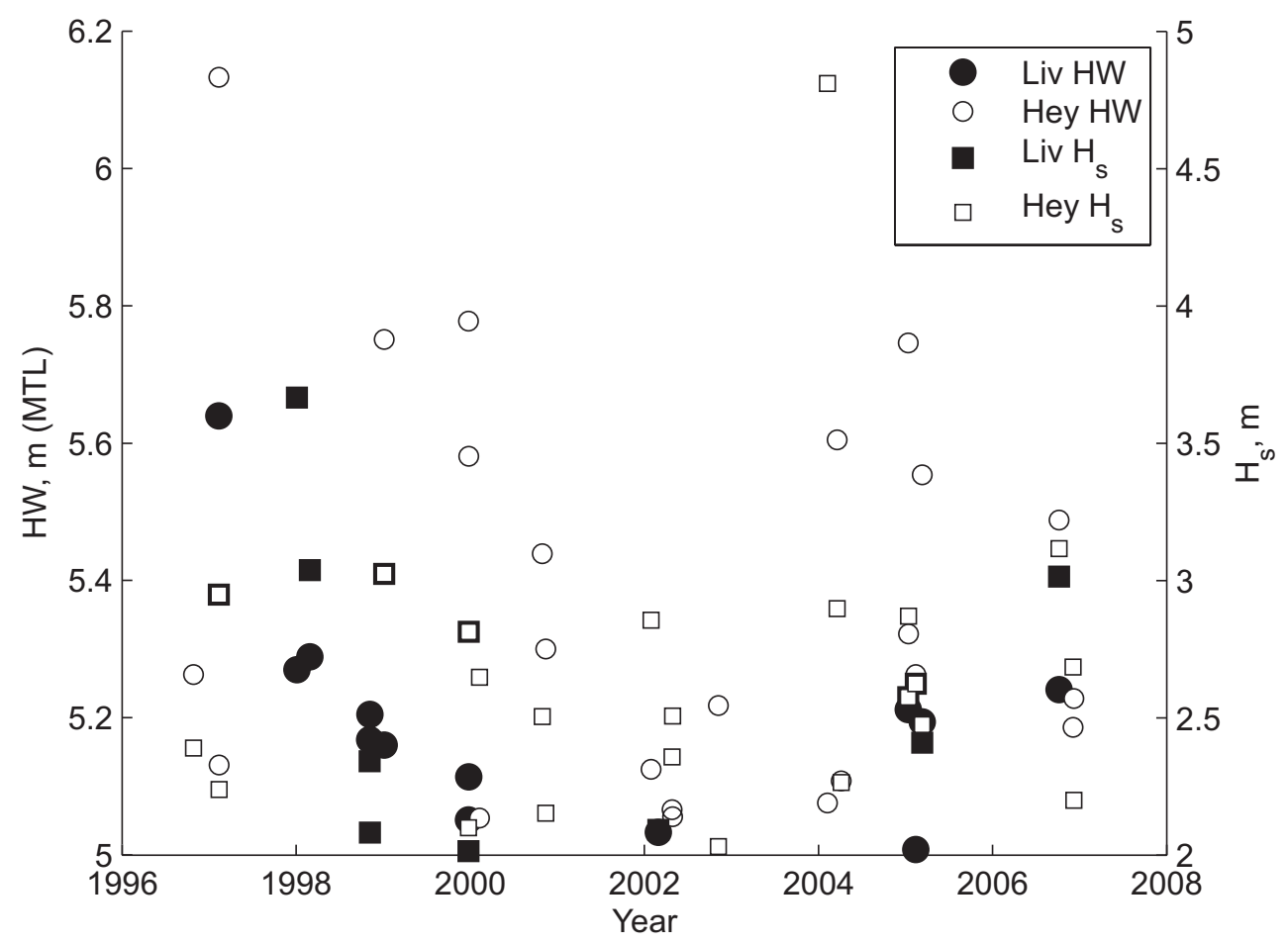

Fig. 8. Periods of coincidental extreme water levels and wave events. Observed high water (HW) levels exceeding 5m at Liverpool and Heysham, with modelled offshore wave heights $\left(H_{s}\right)$ exceeding $2 \mathrm{~m}$ at the wave buoy location, coincidental with $\mathrm{HW}$ at one of the ports.

Next we investigate the frequency of extreme events and look for trends over the past decade. For each year the peak surge level and number of occurrences the peak of a surge event exceeds $0.5 \mathrm{~m}$ is given in Table 6 . No obvious trend exists over the past decade (Table 6, Figures $4-6$ ), due to the short time period to detect long-term trends. But the greatest occurrence of large surges $(>0.5 \mathrm{~m})$ occurred in the second half of the decade. The largest peaks are more evenly distributed across the years. Neither end of this coastline is consistently experiencing larger tide-surge residuals than the other end. But there is a slight bias for surge residuals greater than $0.5 \mathrm{~m}$ to occur more frequently at the Heysham (northern) end of the coastline. This location has also experienced the largest surges over the last decade. At Heysham extreme 
wind events have a more significant impact on the water level, since the filtered-surge residual is often greater and more frequently above $0.5 \mathrm{~m}$ compared with Liverpool.

\begin{tabular}{|l|l|l|l|l|l|l|l|l|l|}
\hline & \multicolumn{2}{|l|}{$\begin{array}{l}\text { Liverpool surge } \\
\text { residual }\end{array}$} & \multicolumn{2}{l|}{$\begin{array}{l}\text { Liverpool filtered } \\
\text {-surge residual }\end{array}$} & \multicolumn{2}{l|}{$\begin{array}{l}\text { Heysham surge } \\
\text { residual }\end{array}$} & \multicolumn{2}{l|}{$\begin{array}{l}\text { Hesysham filtered } \\
\text {-surge residual }\end{array}$} \\
\hline Year & Peak & $\begin{array}{l}\text { Occurrence } \\
>0.5 \mathrm{~m}\end{array}$ & Peak & $\begin{array}{l}\text { Occurrence } \\
>0.5 \mathrm{~m}\end{array}$ & Peak & $\begin{array}{l}\text { Occurrence } \\
>0.5 \mathrm{~m}\end{array}$ & Peak & $\begin{array}{l}\text { Occurrence } \\
>0.5 \mathrm{~m}\end{array}$ \\
\hline 1996 & 1.48 & 52 & 1.11 & 13 & 1.54 & 52 & 1.25 & 23 \\
\hline 1997 & 2.19 & 66 & 1.01 & 18 & 1.86 & 70 & 1.04 & 14 \\
\hline 1998 & 1.99 & 91 & 1.16 & 20 & 2.41 & 14 & 1.37 & 5 \\
\hline 1999 & 1.75 & 108 & 0.91 & 31 & 1.61 & 118 & 1.10 & 42 \\
\hline 2000 & 1.70 & 107 & 0.96 & 34 & 2.12 & 137 & 1.05 & 47 \\
\hline 2001 & 1.04 & 55 & 0.72 & 15 & 1.06 & 65 & 0.87 & 36 \\
\hline 2002 & 2.26 & 83 & 0.94 & 27 & 1.54 & 140 & 1.06 & 47 \\
\hline 2003 & 0.76 & 21 & 0.63 & 5 & 1.07 & 111 & 0.95 & 49 \\
\hline 2004 & 1.50 & 161 & 0.85 & 50 & 1.62 & 256 & 1.06 & 86 \\
\hline 2005 & 1.71 & 90 & 1.19 & 23 & 2.08 & 88 & 1.24 & 31 \\
\hline 2006 & 1.57 & 224 & 1.16 & 77 & 1.56 & 135 & 1.31 & 45 \\
\hline
\end{tabular}

Table 6. The peak annual surge and filtered-surge residuals and the occurrence of surge events with peak greater than $0.5 \mathrm{~m}$ when observations are available at Liverpool and Heysham.

Over the last 11 years the occurrence of surges and HW greater than specified levels is given in the following tables $(7-9)$. Table 7 shows surges $>1 \mathrm{~m}$, while Table 8 shows surges $<1 \mathrm{~m}$ and Table 9 shows total water level (MTL). Often the frequency of separate surge events above an extreme specified value is less at Heysham than at Liverpool (Table 7). Table 8 shows that the frequency of smaller filtered-surges is greater at Heysham than Liverpool. Heysham has a greater tidal range than Liverpool so achieves higher HW levels (Table 9). But the three most extreme HW levels for each location are generally achieved with a similar number of occurrences at both locations, a consequence of the locations not experiencing independent events.

\begin{tabular}{|l|l|l|}
\hline Surge level & Liverpool & Heysham \\
\hline$>1.0 \mathrm{~m}$ & 100 & 99 \\
\hline
\end{tabular}




\begin{tabular}{|l|l|l|}
\hline$>1.5 \mathrm{~m}$ & 19 & 11 \\
\hline$>1.7 \mathrm{~m}$ & 10 & 4 \\
\hline$>1.9 \mathrm{~m}$ & 6 & 3 \\
\hline$>2.1 \mathrm{~m}$ & 2 & 3 \\
\hline
\end{tabular}

Table 7. The number of occurrences the observed surge residual exceeds the levels specified in the table at Liverpool and Heysham.

\begin{tabular}{|l|l|l|}
\hline Filtered-Surge level & Liverpool & Heysham \\
\hline$>0.5 \mathrm{~m}$ & 313 & 425 \\
\hline$>0.7 \mathrm{~m}$ & 73 & 117 \\
\hline$>1.0 \mathrm{~m}$ & 9 & 12 \\
\hline
\end{tabular}

Table 8. The number of occurrences the observed filtered-surge residual exceeds levels specified in the table at Liverpool and Heysham.

\begin{tabular}{|l|l|l|}
\hline HW level & Liverpool & Heysham \\
\hline$>5.0 \mathrm{~m}$ & 50 & 289 \\
\hline$>5.2 \mathrm{~m}$ & 16 & 125 \\
\hline$>5.4 \mathrm{~m}$ & 3 & 40 \\
\hline$>5.6 \mathrm{~m}$ & 1 & 17 \\
\hline$>5.8 \mathrm{~m}$ & 0 & 5 \\
\hline$>6.0 \mathrm{~m}$ & 0 & 2 \\
\hline
\end{tabular}

Table 9. The number of occurrences the observed high water level (MTL) exceeds levels specified in the table at Liverpool and Heysham.

Table 10 shows how frequently the modelled peak of separate wave events in Liverpool Bay exceeds $3 \mathrm{~m}$ and what is the peak wave height achieved each year. The most extreme annual wave event often exceeds $4.0 \mathrm{~m}$ and is often $(6-18$ times per year) greater than $3.0 \mathrm{~m}$. In 2002 the largest wave height and greatest number of extreme events occurred. There is no obvious trend in the data suggesting a long-term increase in intensity and frequency of extreme wave conditions in relation to climate change over this short period. The data do imply that there is some inter-annual variability in wave intensity (Fig 7, Table 10) with peak conditions exceeding $5 \mathrm{~m}$ for 
two consecutive years over an interval of 7 years. A longer time series of data is required to verify any pattern. In table 11 we show that waves greater than $4 \mathrm{~m}$ have been fairly infrequent over the past decade, whereas $3.0 \mathrm{~m}-4.0 \mathrm{~m}$ waves are quite common.

\begin{tabular}{|l|l|l|}
\hline & \multicolumn{2}{|l|}{$\begin{array}{l}\text { Liverpool Bay wave } \\
\text { height }\end{array}$} \\
\hline Year & Peak & Occurrence $>3.0 \mathrm{~m}$ \\
\hline 1996 & 4.50 & 6 \\
\hline 1997 & 5.63 & 7 \\
\hline 1998 & 5.39 & 7 \\
\hline 1999 & 4.02 & 11 \\
\hline 2000 & 4.09 & 10 \\
\hline 2001 & 4.05 & 3 \\
\hline 2002 & 4.09 & 18 \\
\hline 2003 & 3.90 & 12 \\
\hline 2004 & 5.03 & 9 \\
\hline 2005 & 5.46 & 11 \\
\hline 2006 & 4.09 & 7 \\
\hline
\end{tabular}

Table 10. The peak annual significant wave height and the number of events the wave height exceeds $3.0 \mathrm{~m}$ from model hindcast at the Liverpool wave buoy location.

\begin{tabular}{|l|l|}
\hline$H_{s}$ & Liverpool \\
\hline$>3.0 \mathrm{~m}$ & 101 \\
\hline$>3.5 \mathrm{~m}$ & 40 \\
\hline$>4.0 \mathrm{~m}$ & 15 \\
\hline$>5.0 \mathrm{~m}$ & 4 \\
\hline
\end{tabular}

Table 11. The number of occurrences the modelled peak significant wave height $\left(H_{s}\right)$ for an event exceeds levels specified in the table in Liverpool Bay.

\section{Return periods}

We use the General Extreme Value (GEV) method with a linear trend to determine the return periods of extreme events in Liverpool Bay. Table 12 shows the estimated high water levels and wave heights that are likely to be exceeded once for the given return period in Liverpool Bay. We analyse observed high water levels to obtain an 
idea of the most extreme total water level along the Sefton Coast and the wave height in Liverpool Bay as this will lead to defence overtopping, especially if combined with extreme water levels. These estimated levels give an idea of the likelihood of extreme present day events causing coastal inundation due to surges increasing the total water level and wave overtopping. We see that the 100 -year peak total water is $0.8 \mathrm{~m}-1 \mathrm{~m}$ above the typical extreme annual storm level. The 100-year extreme wave height is $7.3 \mathrm{~m}, 3.2 \mathrm{~m}$ greater than the typical extreme annual storm level. Over a long-term (100 year period) wave over topping due to extreme waves is more likely to cause coastal flooding compared with extreme total water levels, as significant increases in the extreme wave height occur within low return period. Large annually occurring events are considered to have total water levels above $5.2 \mathrm{~m}$ for Liverpool and of $5.6 \mathrm{~m}$ for Heysham and/or wave heights exceeding 4m, i.e. a 1 year return period. Extreme events are defined by water levels and wave heights that exceed the 5 year return period, given in Table 12 .

\begin{tabular}{|l|l|l|l|l|l|l|}
\hline & \multicolumn{2}{|l|}{ Liverpool } & \multicolumn{3}{l|}{ Heysham } & \multicolumn{2}{l|}{ Wave buoy } \\
\hline $\begin{array}{l}\text { Return } \\
\text { Period, yrs }\end{array}$ & $\begin{array}{l}\mathrm{HW} \text { level, } \\
\mathrm{m}\end{array}$ & $\begin{array}{l}\text { Error, } \\
\mathrm{m}\end{array}$ & $\begin{array}{l}\text { HW level, } \\
\mathrm{m}\end{array}$ & $\begin{array}{l}\text { Error, } \\
\mathrm{m}\end{array}$ & $H_{s}, \mathrm{~m}$ & $\begin{array}{l}\text { Error, } \\
\mathrm{m}\end{array}$ \\
\hline 1 & 5.22 & 0.04 & 5.66 & 0.05 & 4.09 & 0.15 \\
\hline 2 & 5.30 & 0.05 & 5.79 & 0.07 & 4.49 & 0.22 \\
\hline 5 & 5.41 & 0.09 & 5.98 & 0.13 & 5.05 & 0.38 \\
\hline 10 & 5.52 & 0.14 & 6.12 & 0.18 & 5.52 & 0.57 \\
\hline 20 & 5.65 & 0.23 & 6.28 & 0.25 & 6.01 & 0.83 \\
\hline 25 & 5.69 & 0.27 & 6.33 & 0.28 & 6.18 & 0.93 \\
\hline 50 & 5.84 & 0.41 & 6.49 & 0.38 & 6.73 & 1.28 \\
\hline 100 & 6.02 & 0.61 & 6.67 & 0.49 & 7.31 & 1.72 \\
\hline 1000 & 6.82 & 1.84 & 7.30 & 1.02 & 8.84 & 3.12 \\
\hline
\end{tabular}

Table 12: The return periods for high water (HW) levels (MTL) at Liverpool and Heysham along the Sefton coast and for wave heights $\left(H_{s}\right)$ at the wave buoy location in Liverpool Bay. 
The joint probability of major water levels and corresponding wave conditions in Liverpool Bay is investigated, using the 11 year data sets. Over this period data was available for 6919 high waters at Liverpool and for 6306 high waters at Heysham. The modelled offshore wave heights at the time of every observed high water during the study period are plotted for water levels at Liverpool (Fig. 9) and Heysham (Fig. 10). The actual wave heights at the coast will be lower than those presented as the waves will shoal as they propagate towards the coast away from the wave buoy location. Using the JOIN-SEA software, freely available from HR Wallingford, the joint probability of waves and water levels was determined using the method described by Hawkes (2000). The contours of equal joint exceedance are shown in Figures 9 and 10 for different return periods. The worst case water level - wave height pairs at Heysham are $(4.90,5.40)$ and $(5.07,4.81)$ (Fig. 10). At Liverpool the worst case pairs are slightly lower, taking values of $(4.82,5.40)$ and $(4.50,4.81)$ (Fig. 9). For both locations these worst case pairs have a return period of over 50 years.

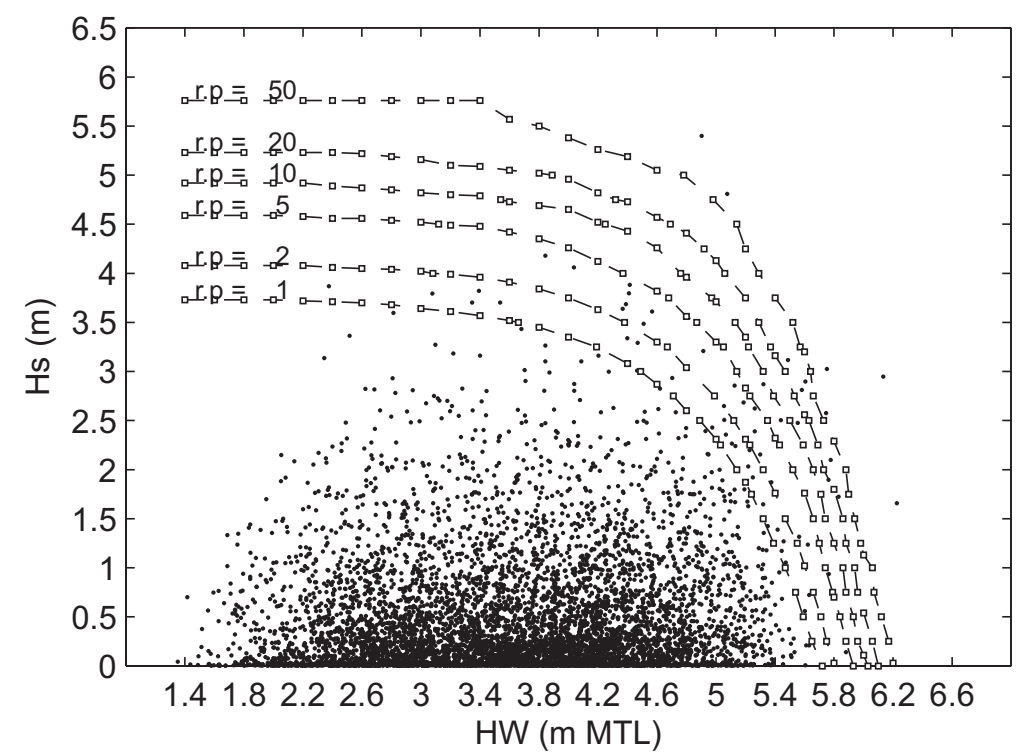

Fig. 9. Wave heights $\left(H_{s}\right)$ during high water (HW) at Liverpool during $1996-2006$. The contours show the equal joint exceedance probability for a range return periods (r. p.), predicted by the JOIN-SEA software. 


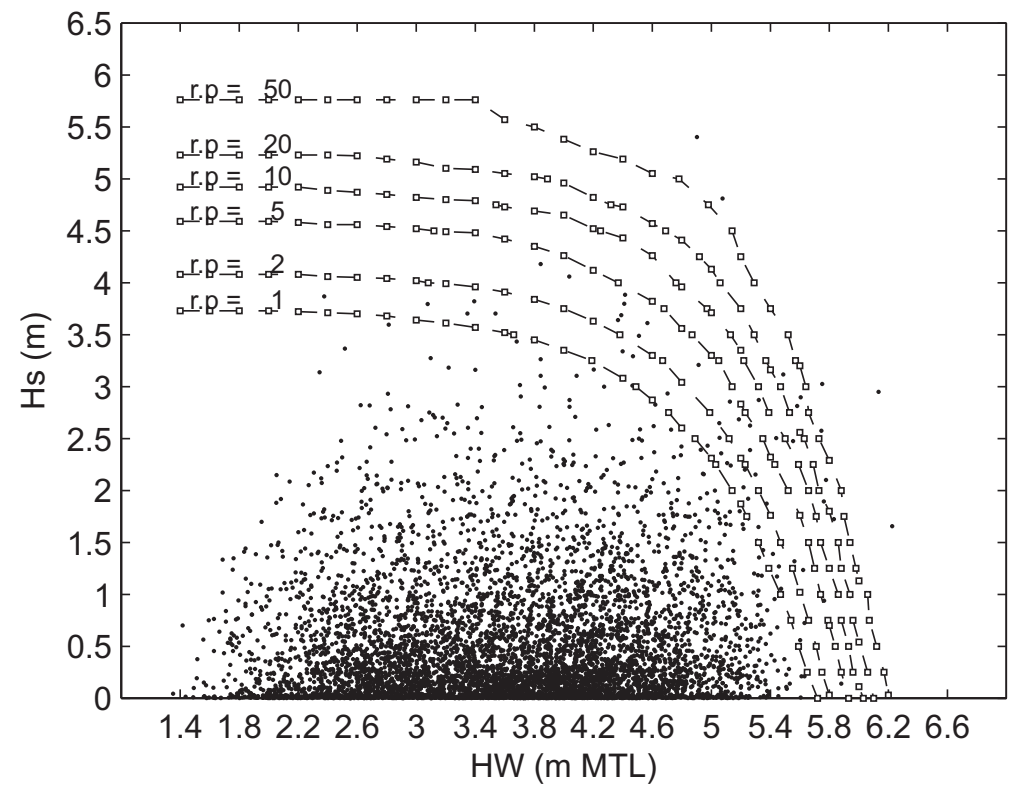

Fig. 10. Wave heights $\left(H_{s}\right)$ during high water $(\mathrm{HW})$ at Heysham during $1996-2006$.

The contours show the equal joint exceedance probability for a range return periods (r. p.), predicted by the JOIN-SEA software.

\section{Discussion}

A nested POLCOMS-WAM modelling system has been run for an 11year period to allow long-term validation of the models and provide model data to investigate surges in the eastern Irish Sea.

Validation of the coarse north east Atlantic (NEA) WAM model has show that the model 'goodness of fit', quantified by $C F$, is very good around the U.K. and within the Irish Sea, i.e. for locations K1, K5, M5, Turbot Bank (TUR) and Seven Stones LV (SEV). Therefore we find this model to have adequate resolution to provide boundary forcing for the Irish Sea model. At the locations M5 and Turbot Bank (TUR) the 
model accuracy is slightly lower for $T$ (higher $C F$ value) than at the other three locations around the Irish Sea and compared with the $H_{s}$ accuracy. At these two locations $T$ is slightly over-predicted (positive pbias $T$ ). The most likely cause of this is lack of detail in the bathymetry, which has constant depth of $600 \mathrm{~m}$, and coastline in and around the Irish Sea allowing more swell into the Irish Sea than would occur in reality. Improved wind forcing (in time and space) and bathymetry would help to reduce the systematic under-prediction in $H_{s}$ and over prediction of $T$, shown in the Pbias metric.

For the Irish Sea (IRS) the POLCOM-WAM model performs to a 'very good' standard when force by the NEA model and mesoscale wind. Improvements in the resolution of the meteorological forcing in both the IRS and NEA model would further improve the model's performance. Errors in the wind forcing account for some of the discrepancies between the model simulation and the observations, for example, the frequent under-prediction of the wave height.

Surges $>0.5 \mathrm{~m}$ in the eastern Irish Sea may have become more frequent over the last decade (Table 6), but the annual peak in surge does not seem to be getting more intense. Changes in the wind pattern will have a major influence on the filtered surge and wave events. But the time of the wind event relative to the phase (spring-neap) and stage (HW-LW) of the tide will determine the size of the tide-surge residual. For Liverpool the risk of flooding occurs when the total water level exceeds $5.63 \mathrm{~m}$. This is the level reached during the November 1977 surge, which caused significant damage to coastal defences along the Liverpool and Sefton Coast. During LW spring tides the largest local surge residual will be generated but the total water level 
compared to spring HW level will be insignificant, and thus not pose a flood risk. During HW spring tide the wind will have least effect locally and the tide-surge interaction can act to reduce the surge at the peak of the tide. Hence, the likelihood of water levels significantly exceeding the spring HW level is low. For example at Liverpool a $2.26 \mathrm{~m}$ surge residual occurred on the $27 / 10 / 02$ and a $2.12 \mathrm{~m}$ surge residual occurred on the 24/12/97. The peak HW levels during these events were $3-3.7 \mathrm{~m}$ (MTL), which does not pose a flood risk. The greatest HW level of 5.64m (MTL) at Liverpool occurred on the $10 / 02 / 97$. The surge level at this time was $0.61 \mathrm{~m}$ and the peak in the surge level was $0.76 \mathrm{~m}, 30$ minutes after HW. Interestingly, the filteredsurge at the time of HW was $0.755 \mathrm{~m}$ and at the time of the peak in tide-surge residual it was $0.758 \mathrm{~m}$. This demonstrates the tide-surge interaction during the largest HW levels acts to reduce the magnitude of the wind driven (filtered-) surge on the total water level.

Heysham experiences more frequent smaller $(<1 \mathrm{~m})$ surges than Liverpool (Table 6 8 , Figure 5) and less extreme $(>1 \mathrm{~m})$ surges. But when a large surge does occur it is often more intense than those experienced at Liverpool. Heysham is more exposed to surge-generating wind events (more frequent filtered-surge events $>0.5 \mathrm{~m}$ ) than Liverpool, but the larger tidal range interacting with the surge seems to reduce the frequency of extreme surge events $(>0.5 \mathrm{~m})$ and extreme HW $(>5.2 \mathrm{~m}$, MTL) events. Although infrequent, when the peak surge occurs during lower water levels, the larger tidal range at Heysham is the cause of the more intense surge compared with Liverpool. Finally the larger tidal range means the maximum HW levels are greater at Heysham than Liverpool. 
Waves are locally generated in Liverpool Bay (Brown and Wolf, 2009). Winds from the northwest and west have the longest fetches, thus generate the most severe wave conditions. Hence if winds from these directions become more intense and frequent, so will the extreme wave conditions. Interestingly the most severe surge conditions occurred when the winds were from the south west. Since the external surge has a dominant contribution to the surge in the eastern Irish Sea this direction provides longest fetch for surge generation. The coast is therefore at most risk from flooding when a south-westerly wind veers to the west during HW spring tide. Under these conditions substantial wave heights coincide with a low to moderate surge on top of extreme tidal levels. This leads to a high risk of defences being overtopped (e.g. November 1977, Jones and Davies, 1998).

By classify extreme events as those with a 5 year return period to, we find that for the Sefton coastline a $5.05 \mathrm{~m}$ offshore wave height with extreme high water levels of $5.98 \mathrm{~m}$ at Heysham and 5.41 at Liverpool is considered extreme (Table 12). Every year it is likely that a wave height of $2.6 \mathrm{~m}$ will coincide with a high water level of 4.4m at Liverpool (Fig. 9) and 4.8m at Heysham (Fig. 9). An example of the worst joint (5 year) extreme conditions is an offshore wave height of $3.0 \mathrm{~m}$ coinciding with high water of $4.7 \mathrm{~m}$ at Liverpool (Fig. 9) and an offshore wave height of $3.25 \mathrm{~m}$ coinciding with high water of $5.1 \mathrm{~m}$ at Heysham (Fig. 10).

This study shows that in the eastern Irish Sea (locations with large tidal range) the surge residual is a better measure for flood risk management compared with the filtered-surge. Since the tide can significantly enhance or reduce the surge due to the meteorological forcing alone. The surge residual represents the additional water level 
that will be experienced on top of the tidal level, hence allowing assessment of the flood risk posed at HW due to enhanced water levels.

The medium resolution Irish Sea model applied here has proven to be a valid modelling system for the long-term. These data will be used to investigate the meteorological conditions that have caused the most extreme surges and waves within the eastern Irish Sea over the past decade. The worst storm events in this region will be isolated and the model data used to provide boundary forcing for a high resolution (185m) Liverpool Bay model. At this resolution additional physics will be included to investigate these isolated extreme events that pose flood risk along the Sefton coastline. For example, 'wetting and drying' of tidal flats, wave setup, effects of density stratification on the surge events and the resulting morphological change will be included.

Finally, we discuss the metrics used to validate the model. We find that there is discrepancy between which metric determines which variables are most accurately modelled. For example, the $C F$ metric finds the wind speed to be more accurately simulated, while the $\mid$ pbias $\mid$ metric finds the wind direction to be more valid. Confidence is gained when both metrics agree the model performance to be in similar categories, although the numerical value may disagree. We feel the $C F$ metric is more appropriate to determine the validity of a variable since is compares the error to the variation in the observation. For tide, surges and waves the variation is important as it determines if a flood risk is posed. The pbias is a good indicator for over- or underprediction, but the validity is likely to improve for large data sets since the long-term errors cancel each other out and the summation of the data in the denominator will 
grow larger, reducing the percentage error. The error is compared to the size of the data, which is more appropriate for variable that have low variability in time.

\section{Conclusion}

An 11-year hindcast has been performed using the POLCOM-WAM nested modelling system for the Irish Sea. The model data has been validated across the Irish Sea using 19 tide gauges and 22 wave stations. We find that the model hindcast is valid in the long-term. Initial analysis of the data has shown that extreme surges in Liverpool Bay can reach $1.37 \mathrm{~m}$ as a result of the meteorological forcing alone. Surge levels due to tide-surge interaction can reach $2.41 \mathrm{~m}$, demonstrating the importance of the tide in this region. The largest surge in the past 11 years reached $2.26 \mathrm{~m}$ at Liverpool on the $27^{\text {th }}$ October 2002. Since the largest surges do not occur during high water levels the most extreme high water levels only exceed the spring tide high water level by less than a metre. The largest high water levels achieved in the past decade was $6.18 \mathrm{~m}$ (MTL) at Heysham and 5.64m (MTL) at Liverpool. Over the 11-year hindcast period no obvious trend in the intensity and frequency of extreme events is evident as a response to the changing climate. However, future changes in climate during the $21^{\text {st }}$ century are likely to be more significant and will be investigated in future work.

The largest surges are likely to occur during low water levels, thus do not pose significant flood risk. Heysham has less frequent but more intense surges, and greater flood risk due to a larger tidal range compared with Liverpool. Waves also pose a flood risk due to overtopping. In Liverpool Bay the largest hindcast waves have reached $5.63 \mathrm{~m}$ in the last decade. The worst flood risk occurs when a significant wind event occurs close to high water. As any surge increases the high water levels 
and large waves are also generated. The tidal range at the time of the surge event will control the magnitude of the additional water level on top of the tide. Every five years the extreme high water level likely to be exceeded is $5.41 \mathrm{~m}$ (MTL) at Liverpool and $5.98 \mathrm{~m}$ (MTL) at Heysham, but will remain below 5.52m (MTL) and $6.12 \mathrm{~m}$ (MTL) respectively. The extreme offshore wave height likely to be exceeded is $5.05 \mathrm{~m}$, while remaining under $5.52 \mathrm{~m}$. In the past 11 years such extreme wave and water levels have not been achieved simultaneously. The worst extreme conditions from the data presented here was a 5.1m (MTL) high water at Heysham coinciding with $4.8 \mathrm{~m}$ waves offshore. From the modelling work presented and tide gauge observations there is no suggestion that extreme events (waves, surges, high water levels) are becoming larger or more frequent.

\section{Acknowledgments}

The CoFEE project is funded under the NERC Flood Risk in Extreme Environments (FREE) program and the MICORE project is funded by the EU FP7 program. Thanks to Jane Williams (POL), the Operational surge model output and meteorological data was provided over the 11-year period. Meteorological data was also obtained from ECMWF to drive the coarse WAM model. Phil Knight (POL) is thanked for providing a tidal analysis program to validate the model data. Measured data for these validations were obtained from BODC, CEFAS and both the U.K. and Irish Met. Offices. David Blackman (POL) is thanked for his assistance in using generalised extreme value statistics to calculate return periods and for guidance in using the HR Wallingford JOIN-SEA software to investigate the joint probability of extreme events. 


\section{References}

Allen, J.I., Holt, J.T., Blackford, J., Proctor, R., 2007. Error quantification of a highresolution coupled hydrodynamic-ecosystem coastal-ocean model: Part 2. Chlorophyll-a nutrients and SPM. Journal of Marine Systems, 68(3-4), $381-404$.

Ashworth, M., Holt, J.T., Proctor, R., 2004. Optimization of the POLCOMS hydrodynamic code for terascale high-performance computers. Proceedings of the $18^{\text {th }}$ International parallel and distributed processing symposium, $26^{\text {th }}-30^{\text {th }}$ April, Santa Fe, Ne Mexico.

Brown, J.M., Souza, A.J., Wolf, J., 2009. Surge modelling in the Eastern Irish Sea: present and future storm impact, Under review in Ocean Dynamics, special issue: PECS 2008: Physics of Estuaries and Coastal Seas, LIVERPOOL, UK, 25-29th August 2008.

Brown, J.M., Wolf, J., 2009. Coupled wave and surge modelling for the eastern Irish Sea and implications for model wind-stress. Continental Shelf Research, 29(10), 1329-1342, doi: 10.1016/j.cr.2009.03.004.

Charnock, H., 1955. Wind-stress on a water surface. Quarterly Journal of the Royal Meteorological Society, 81(350), 639-640.

Craig, P.D., Banner, M.L., 1994. Modeling wave-enhanced turbulence in the ocean surface layer. Journal of Physical Oceanography, 24, 2546-2559.

Flather, R.A., 1994. A storm surge model of the northern Bay of Bengal with application to the cyclone disaster in April 1991. Journal or Physical Oceanography, 41(1), 172-190.

Flather, R.A., 2000. Existing operational oceanography. Coastal Engineering, 41(1-3), 13-40. 
Hawkes, P.J., 2000. The joint probability of waves and water levels: JOIN-SEA, A rigorous but practical new approach, HR Report SR 537, HR Wallingford, Oxford, pp. 244.

Holt, J.T., James, D.J., 2001. An s coordinate density evolving model of the northwest European continental shelf: 1, Model description and density structure. Journal of Geophysical Research, 106(C7), 14,015-14,034.

Houghton, J., 2005. Global warming. Reports on Progress in Physics, 68(6), $1343-1403$.

IPCC, 2007. IPCC Fourth Assessment Report, Climate Change 2007 Synthesis Report. Pachauri, R.K. and Reisinger, A. (Eds.), Cambridge University Press, UK. IPCC, Geneva, Switzerland, 104pp.

Janssen, P.A.E.M., 2004. The interaction of ocean waves and wind. Cambridge University Press, Cambridge, 300pp.

Jones, J.E., Davies, A.M., 1998. Storm surge computations for the Irish Sea using a three-dimensional numerical model including wave-current interaction. Continental Shelf Research, 18(2), 201-251.

Komen, G.J., Cavaleri, L., Donelan, M., Hasselmann, K., Hasselmann, S., Janssen, P.A.E.M., 1994. Dynamics and modelling of ocean waves. Cambridge University Press, Cambridge, 532pp.

Lamb, H., 1991. Historic storms of the North Sea, British Isles and Northwest Europe. Cambridge University press, Cambridge, 204pp.

Lennon, G.W., 1963. The identification of weather conditions associated with the generation of major storm surges along the west coast of the British Isles. Quarterly Journal of the Royal Meteorological Society, 89, 381-394. 
Madsen, O.S., 1994. Spectral wave-current bottom boundary layers flows. Proceedings of the $24^{\text {th }}$ ICCE. ASCE 1, 384-398.

Mellor, G.L., Yamada, T., 1982. Development of a turbulence closure model for geophysical fluid problems. Review of geophysics and Space Physics, 20, No. $4,851-875$.

Monbaliu, J., Padilla-Hernández, R., Hargreaves, J.C., Carretero-Albiach, J.C., Luo, W., Sclavo, M., Günther, H., 2000. The spectral wave model WAM adapted for applications with high spatial resolution. Coastal Engineering, $41(1-3), 41-62$.

Osuna, P., Souza, A.J., Wolf, J., 2007. Effects of the deep-water wave breaking dissipation on the wind-wave modelling in the Irish Sea. Journal of Marine Systems, 67(1-2), 59-72.

Osuna, P., Wolf, J., 2005. A numerical study on the effect of wave-current interaction processes in the hydrodynamics of the Irish Sea. Proceedings of the 5th International Conference on Ocean Wave Measurement and Analysis: WAVES2005, Madrid, Spain, 10pp.

Pugh, D.T., 2004. Changing sea levels: effects of tides, weather and climate. Cambridge University Press, Cambridge, 265pp.

Pye, K., Blott, S.J., 2008. Decadal-scale variation in dune erosion and accretion rates: An investigation of the significance of changing storm tide frequency and magnitude on Sefton coast, UK. Geomorphology, 102(3-4), $652-666$.

Wolf, J., 2008. Coupled wave and surge modeling and implications for coastal flooding. Advances in Geosciences, 17: 1-4. 
Wolf, J., Brown, J., Lymbery, G., Souza, A., Williams, J., 2008. Coastal flooding in extreme events. Proceedings of the $9^{\text {th }}$ international conference Littoral, $25^{\text {th }}-28^{\text {th }}$ November 2008 , Venice, Italy, $8 \mathrm{pp}$.

Wolf, J., Wakelin, S.L., Holt, J.T., 2002. A coupled model of waves and currents in the Irish Sea. Proceedings of the $12^{\text {th }}$ international Offshore and Polar Engineering Conference, Kitakyushu, Japan, 3, 108-114.

Woodworth, P.L., Blackman, D.L., 2002. Changes in extreme high waters at Liverpool since 1768. International Journal of Climatology, 22(6), $697-714$.

Woodworth, P.L., Flather, R.A., Williams, J.A. Wakelin, S. Jevrejeva, S., 2007. The dependence of the UK extreme sea levels and storm surges on the North Atlantic Oscillation. Continental Shelf Research, 27(7), 935-947.

Zijderveld, A., Verlaan, M., 2004. Towards a new gridded bathymetry for storm surge forecasting in the North Sea. EGU $1^{\text {st }}$ General Assembly, Nice, France, 25-30 April 2004, Geophysical Research Abstracts, 6, EGU04-A-05177. 